\title{
Disponibilidad de Flúor en Saliva y Biofilms en Escolares Expuestos a Leche o Agua Fluorurada
}

\author{
Availability of Fluoride in Saliva and Biofilms in School \\ Children Exposed to Fluoride in Water or Milk
}

\author{
Patricia Muñoz Millán*; Gerardo Espinoza Espinoza*; Gabriel Nuñez ${ }^{* * *}$ \& Antonio Sanhueza Campos ${ }^{* * *}$
}

MUÑOZ, M. P.; ESPINOZA, E. G.; NUÑEZ, G. \& SANHUEZA, C. A. Disponibilidad de flúor en saliva y biofilms en escolares expuestos a leche o agua fluorurada. Int. J. Odontostomat., 9(3):393-398, 2015.

RESUMEN: La caries sigue siendo un problema de Salud Pública, por la alta prevalencia y severidad que afecta a la población. En Chile, la incorporación de flúor en el agua y la leche, son medidas de salud pública en la prevención de caries que se distribuye en zonas urbanas y rurales respectivamente. La evidencia científica nos permite sostener que el fluoruro disponible en saliva y placa bacteriana es el principal responsable del efecto preventivo de este compuesto en el proceso de caries. El objetivo fue comparar los niveles de flúor en saliva y placa bacteriana, antes y después de la ingesta de leche, de los escolares que consumen leche fluorurada y de los que consumen leche sin flúor preparada con agua potable fluorurada de la Región de la Araucanía de Chile. Se realizó un estudio de muestras repetidas de saliva y placa bacteriana en 165 niños(as) incorporados(as) en el Programa PAE de 16 escuelas rurales y urbanas. Se tomaron muestras de saliva y placa bacteriana antes del desayuno, muestras de saliva 60 min después y muestras de placa bacteriana 120 minutos después del desayuno. La concentración de fluoruro en saliva se observa muy similar sin importar el vehículo a través del cual se le administre, sea este leche fluorurada o leche sin fluor preparada con agua fluorurada, tanto en las muestras basales como en las muestras obtenidas después del desayuno. En cambio en placa bacteriana si se observan pequeñas diferencias que, siendo estadísticamente significativa, pueden no tener mucha relevancia clínica por ser demasiado pequeñas. Estos resultados refuerzan la hipótesis de que la estrategia de leche fluorurada tiene resultados similares al agua fluorurada.

PALABRAS CLAVE: fluoruro, prevención, caries, saliva, agua fluorada, leche fluorada.

\section{INTRODUCCIÓN}

La caries sigue siendo un problema de Salud Pública, por la alta prevalencia y severidad que afecta a la población. Actualmente en Chile, la incorporación de flúor en el agua y la leche, son medida de salud pública en la prevención de caries que se distribuye en zonas urbanas y rurales respectivamente (Mariño et al., 2001, 2007). Existe una fuerte evidencia de que la fluoruración de las aguas es efectiva para controlar las caries dental dentro de las comunidades (Mitchell et al., 2007). Pero, si bien, la cobertura de la fluoruración del agua potable es alta en zonas urbanas a través de la red de agua, no llega de la misma manera a las zonas rurales, donde la leche fluorurada se presenta como un vehículo alternativo para llegar con flúor a esta población (Yeung \& Tickle, 2002), la leche fluorurada se distribuye a escolares de las zonas rurales de chile, a través del Programa de Alimentación Escolar (PAE) entregada por el Ministerio de Educación de dicho pais (Mariño et al., 2007; Weitz et al., 2007).

La evidencia científica nos permite sostener que el fluoruro disponible en saliva y placa bacteriana es el principal responsable del efecto preventivo de este compuesto en el proceso de caries (Newby et al., 2013; Naumova et al., 2012; Nakano et al., 2011; Yeung,

Odontopediatra, Magister Epidemiología Clínica, Departamento de odontopediatria, Universidad de La Frontera, Temuco, Chile.

* Odontólogo, Magister Epidemiología Clínica, Docente Asistente, Departamento Salud Pública, Universidad de La Frontera, Temuco, Chile.

*** Bioquímico, Departamento Cs.Básicas, Universidad de La Frontera, Temuco, Chile.

${ }_{* \star * *}$ Bioestadística, Docente Departamento Matemáticas y Estadísticas, Universidad de La Frontera, Temuco, Chile.

Proyecto financiado por la universidad de la Frontera a través de DIUFRO DI09-0034 
2008; Vallejos et al., 2002). Es por eso que resulta interesante determinar la concentración de flúor tanto en saliva como en placa ya que es a través de ellos que el flúor ingerido, ya sea de leche o agua fluorurada se pone en contacto con la superficie dentaria para actuar en la remineralización del esmalte (Lynch et al., 2004; Petersson et al., 2002; Boros et al., 2001; Twetman et al., 1998). El objetivo de esta investigación es determinar y comparar los niveles de flúor en saliva y placa bacteriana, antes y después de la ingesta de leche, de los escolares que consumen leche fluorurada y de los que consumen leche sin flúor preparada con agua potable fluorurada de la Región de la Araucanía de Chile.

\section{MATERIAL Y MÉTODO}

Se realizó un ensayo no controlado del tipo antes-después donde se tomaron muestras para ver la concentración de flúor en la saliva y la placa bacteriana de las bocas de los niños, antes y después de la exposición a leche, ya sea que el polvo o el agua con que la preparan sea fluorurado.

La población Accesible estaba constituida por los escolares pertenecientes a la provincia de Cautín,
Región de la Araucanía, de zonas rurales incorporados al programa de alimentación escolar fluorurado, (PAEF), y escolares de zonas urbanas, con acceso a agua potable fluorada en su escuela, incorporados al programa de alimentación escolar (PAE), entre 6 y 12 años durante el año 2009.

Para el cálculo de tamaño muestral se utilizó información de trabajos publicados y del estudio preliminar desarrollado por la investigadora. Se utilizó el programa estadístico Epidat, como se trata de una muestra por conglomerado se estimó un efecto de diseño para esta muestra de 2,4 . El tamaño de la muestra considerando un alfa de 0,05 y una potencia de $90 \%$ y una Desviación Estándar desconocida pero igual para ambos grupos, y una diferencia estandarizada de $0,83(0,05 / 0,06)$ es de un total de 75 niños en cada grupo (31 por 2,4=75).

De esta población accesible la selección de la muestra se realizó en dos etapas (Fig. 1). Un primer muestro por conglomerado nos permitió elegir un total de 16 escuelas, 8 escuelas urbanas en las que la leche se prepara con agua fluorurada y otras 8 escuelas rurales en la leche en polvo contiene fluor. En una segunda etapa el muestreo fue aleatorio simple, para seleccionar 10 niños en cada escuela, a estos niños se les entregó un consentimiento informado para que

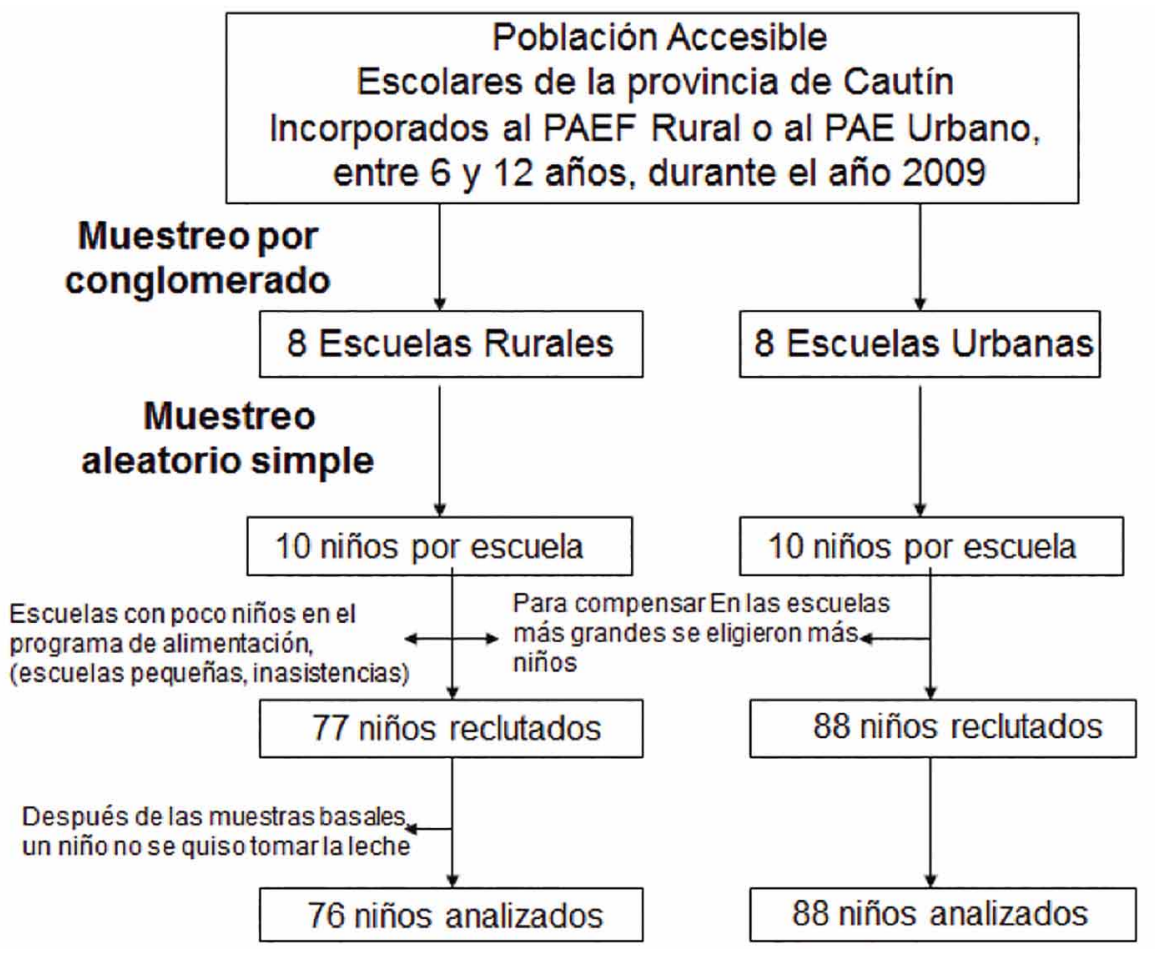

Fig. 1. Diagrama de reclutamiento de la investigación realizada. 
fuera firmado por sus padres como requisito para autorizar su participación en el estudio. En este punto se suscitó el siguiente inconveniente, en las escuelas rurales que eran más pequeñas, no siempre habían 10 niños beneficiaros del programa de alimentación, y los 6 o 7 niños presentes en el colegio debieron ser todos elegidos, para compensar se tomó la siguiente medida, en los colegios más grandes y con más niños beneficiarios del programa se eligieron tres o cuatro niños más. Fue así como la muestra quedó constituida por un total de 165 niños, 88 niños urbanos y 77 niños rurales. De los niños rurales, un niño, después de las muestras basales no quiso tomarse la leche,por lo que no fue considerado en los análisis finales.

Para obtener las muestras de saliva se utilizó una goma de mascar sin azúcar para estimular la saliva la que fue recolectada en un recipiente estéril, a su vez la placa bacteriana era recogida de la zona vestibular de los molares superiores con sonda de caries y recolectada en un recipiente estéril. A cada colegio se llegó antes del desayuno, para obtener muestras de saliva estimulada y placa bacteriana previo a dicho desayuno, posteriormente se esperó una hora para obtener la segunda muestra de saliva estimulada y dos horas para obtener la segunda muestra de placa bacteriana, todas las muestras fueron trasladadas en cooler, para mantener la cadena de frío, fueron trasladas a los laboratorios de bioquímica de la Universidad de La Frontera, donde fueron almacenadas en un refrigerador dispuesto para tales fines, en espera del momento de su análisis el cual se realizó a más tardar al día siguiente de la recolección (menos de 24 horas en la mayoría de los casos).

Durante esta visita al colegio, también se llenó una ficha con los antecedentes de identificación del paciente y se recabó información sobre eventuales variables de confusión tales como caries, nivel de higiene oral, edad, sexo, consumo de té, uso de pastas fluoruradas.

Posteriormente, en el laboratorio de bioquímica de la universidad de La frontera, un tecnólogo medico realizó una medición de la concentración del flúor en las muestras de saliva y placa bacteriana. Para las muestras de placa bacteriana: $1^{\circ}$ Se utilizó una técnica de secado, $2^{\circ}$ Se procedió a pesar la muestra, $3^{\circ}$ Se diluyó en $1 \mathrm{ml}$ de agua desionizada y se determinó la concentración de flúor por electrodo de ión específico (96-09, Orion Research Inc., Cambridge, Mass., USA) estandarizado en el rango de 0,01-100 mg/F/l (Ekstrand, 1977), estandarizado con curva de calibra- ción de 0-30 min. Para una muestra de saliva de $2 \mathrm{ml}$, se utilizaron $2 \mathrm{ml}$ de TISAB 4.

Análisis estadístico. Para la caracterización de la población se utilizaron distribuciones de frecuencia según sexo, vehículo de incorporación de fluoruros e higiene oral.

Para medir diferencias en el promedio de la concentración de fluor tanto en saliva como en placa, según el vehículo de incorporación de fluoruros tanto en la muestra basal como en la $2^{\circ}$ muestra, se realizó un ttest para varianzas iguales con el fin de comparar el promedio de dos poblaciones.

Posteriormente se calcularon las diferencias de la concentración de flúor entre la muestra basal y la $2^{\circ}$ muestra, y se analizaron estas diferencias según el vehículo de incorporación. Este análisis de las diferencias se complementó con un modelo de regresión, donde se consideró "la segunda muestra" como resultado final, se calculó por la variable "vehículo de incorporación de flúor" y se ajustó por "la muestra basal" Se había planificado realizar ajustes por otras variables, tales como sexo, nivel placa, exposición a té y a pasta fluorada, concentración del flúor en la leche y en el agua de los colegios, pero como las diferencias entre los grupos comparados fueron tan pequeñas, estas variables de ajuste no fueron necesarias. El Análisis estadístico fue realizado con stata 10.0

\section{RESULTADOS}

La muestra está formada por niños de una edad promedio de 8,42 años, donde 74 son hombres (45\%) y 90 son mujeres (55\%). En esta muestra, $88(54 \%)$ viven en la zona urbana por lo tanto reciben agua fluorurada, y 76 (46\%) viven en la zona rural, es decir, reciben flúor a través de la leche como parte del programa de alimentación escolar. Respecto a la higiene oral, $123(75 \%)$ tienen higiene regular o buena (Sólo tres pacientes tenían higiene buena, es por eso que se decidió agruparlos con los de higiene regular), y 41 (25\%) tienen higiene mala (Tabla I). La distribución del consumo de té y del uso de pasta fluorurada, es muy similar en ambos grupos comparados (Tabla II).

Los resultados de este estudio muestran un promedio basal de fluoruro en saliva de $0,06115 \mathrm{ppm}$ (Grupo Agua Fluorurada (GAF)), de 0,06161 ppm (Grupo Leche Fluorurada (GLF)). Un promedio de 0,06017 
ppm de fluoruro en saliva a los 60 minutos después del desayuno (GAF) y de 0,06048 ppm (GLF). Un promedio de 0,05701 ppm de fluoruro en placa bacteriana basal (GAF), de 0,06022 ppm (GLF), 0,05690 ppm a los 120 minutos después del desayuno (GAF) y de 0,06035 ppm (GLF), los respectivos intervalos de con- fianza se encuentran en la Tabla III.

El promedio de las diferencias de la concentración de flúor entre la medición basal y la segunda muestra tanto en saliva como en placa bacteriana se muestran en la Tabla IV.

Tabla I. Características basales de la muestra al momento del reclutamiento.

\begin{tabular}{|c|c|c|c|c|c|c|c|}
\hline \multirow{3}{*}{ Sexo } & \multirow[b]{3}{*}{ Hombre } & \multicolumn{2}{|c|}{ Agua Fluorurada } & \multicolumn{2}{|c|}{ Leche Fluorurada } & \multirow{2}{*}{\multicolumn{2}{|c|}{ Total }} \\
\hline & & $n=88$ & $(54 \%)$ & $n=76$ & $(46 \%)$ & & \\
\hline & & 44 & $(50 \%)$ & 30 & $(39 \%)$ & 74 & $(45 \%)$ \\
\hline & Mujer & 44 & $(50 \%)$ & 46 & $(61 \%)$ & 90 & $(55 \%)$ \\
\hline Edad & Media $\pm D E$ & \multicolumn{2}{|c|}{$8,42 \pm 0,562$} & \multicolumn{2}{|c|}{$8,08 \pm 0,866$} & \multicolumn{2}{|c|}{$8,26 \pm 0,736$} \\
\hline \multirow[t]{2}{*}{ Nivel de Higiene } & Regular a buena & 73 & $(83 \%)$ & 50 & $(66 \%)$ & 123 & $(75 \%)$ \\
\hline & Mala & 15 & $(17 \%)$ & 26 & $(34 \%)$ & 41 & $(25 \%)$ \\
\hline
\end{tabular}

Tabla II. Frecuencia con que se presentan las variables de confusión medidas en esta muestra al momento del reclutamiento.

\begin{tabular}{llcccccc}
\hline & & \multicolumn{3}{c}{ Agua Fluorurada } & \multicolumn{2}{c}{ Leche Fluorurada } & \multirow{2}{*}{ Total } \\
\cline { 3 - 6 } Consumo & & $\mathbf{n = 8 8}$ & $\mathbf{( 5 4 \% )}$ & $\mathbf{n = 7 6}$ & $\mathbf{( 4 6 \% )}$ & & \\
\cline { 2 - 6 } de té (\%) & No Contesta & 11 & $(13 \%)$ & 8 & $(11 \%)$ & 19 & $(12 \%)$ \\
& $\mathrm{Si}$ & 58 & $(66 \%)$ & 53 & $(70 \%)$ & 111 & $(68 \%)$ \\
Uso de pasta & No & 19 & $(22 \%)$ & 15 & $(20 \%)$ & 34 & $(21 \%)$ \\
dental (\%) & No Contesta & 12 & $(14 \%)$ & 13 & $(17 \%)$ & 25 & $(15 \%)$ \\
& Si & 67 & $(76 \%)$ & 52 & $(68 \%)$ & 119 & $(73 \%)$ \\
& No & 9 & $(10 \%)$ & 11 & $(14 \%)$ & 20 & $(12 \%)$ \\
\hline
\end{tabular}

\section{DISCUSIÓN}

La concentración de fluoruro en saliva y placa bacteriana se observa muy similar sin importar el vehículo a través del cual se le administre, sea este leche fluorurada o agua fluorurada, tanto en las muestras basales como en las muestras obtenidas después del desayuno.

De la comparación de la concentración de fluoruro en las diferentes mediciones según el vehículo de incorporación de flúor se observó que tanto en la muestra basal como en la segunda muestra, la concentración de flúor en la saliva es levemente diferente entre los niños que reciben agua fluorurada de los que reciben leche fluorurada, pero estas diferencias no son estadísticamente significativas ( $p>0,05$, Tabla III), lo que es concordante con lo expuesto por
Petersson et al., quienes realizaron un estudio muy similar determinando concentración de flúor en saliva en niños de 6 a 8 años, después de la ingesta Fcontenido en leche y agua, fue muy similar y sin diferencia estadísticamente significativa $(0,052$ y 0,058 $\mathrm{mg} \mathrm{F/l,} \mathrm{respectivamente).}$

La concentración de flúor en la placa bacteriana es levemente mayor en los que reciben leche fluorurada. Estas diferencias son estadísticamente significativas $(p<0,05)$, pero no es por la ingesta de leche fluorurado, porque es una diferencia que también existe en la medición basal y que se mantiene después de la ingesta por lo que la diferencia no es atribuible únicamente al flúor presente en la leche. 


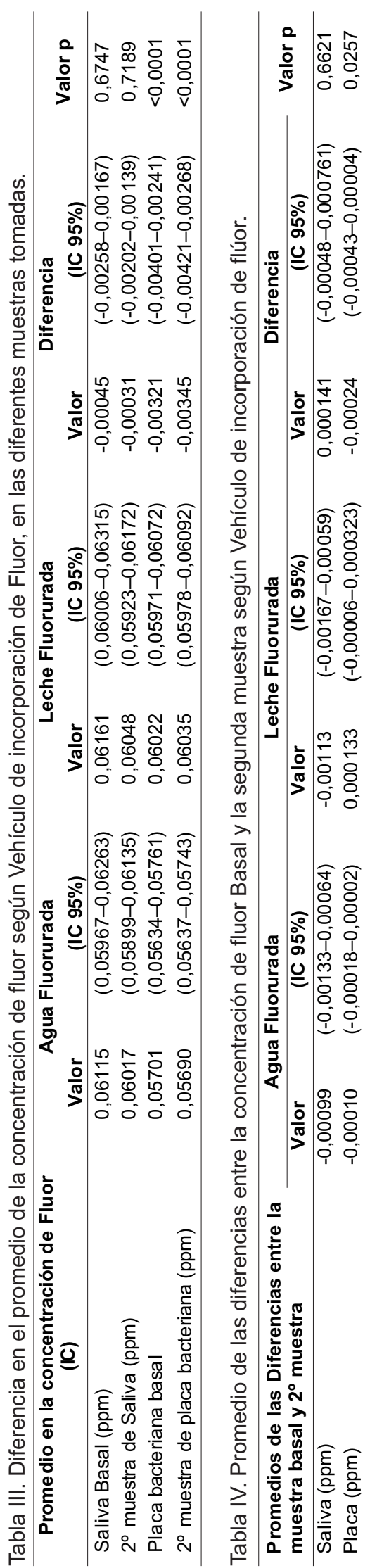

Un aspecto importante del análisis era calcular las diferencias de la concentración de flúor entre la medición basal y la segunda muestra tanto en saliva como en placa bacteriana en cada individuo y luego analizar esas diferencias según el vehículo de incorporación del flúor. En este análisis se observa, que no hay antecedentes para decir que el promedio de las diferencias de las concentraciones de fluor de la muestra basal con la $2^{\circ}$ muestra de saliva, sean distintos entre los niños que reciben agua fluorurada que los que reciben leche fluorurada (Tabla IV).

Al comparar los promedios de las diferencias de las concentraciones de flúor en la muestra basal con la $2^{\circ}$ muestra de placa se observa que las diferencias son mayores en los niños que reciben flúor a través de la leche fluorurada, estas diferencias tienen significancia estadística $(p<0,05$, Tabla IV) estas leves diferencias a favor de la leche fluorurada pueden explicarse porque al comparar dosis únicas de leche fluorurada y leche preparada con agua fluorurada, la primera tiene mayor concentración.

Este análisis de las diferencias se complementó con un modelo de regresión, donde se consideró "la segunda muestra" como resultado final se calculó por la variable "vehículo de incorporación de flúor" y se ajustó por "la muestra basal", tanto para saliva como para placa, en ambos casos los resultados fueron concordantes con los resultados expuestos en los dos párrafos anteriores, es decir sin significancia estadística para saliva, y con significancia estadística para placa, pero nuevamente se observa que las diferencias son tan pequeñas que no alcanzan a ser significativas en el análisis clínico.

Este estudio tiene la fortaleza de haber recabado información de zonas rurales no fluoruradas de nuestra región y compararlas con lo que pasa en zonas más urbanas y la principal limitación del presente estudio es que no entrega reportes de mediciones intermedias que permitieran proyectar el comportamiento de la concentración de flúor a diferentes tiempos, sobre todo en saliva donde el recambio salival pudo afectar las mediciones posteriores a la ingesta.

Estos resultados refuerzan la hipótesis de que la estrategia de leche fluorurada tiene resultados similares al agua fluorurada, basado especialmente en los resultados en saliva, esto es consistente con el estudio de (Mariño et al., 2007) quien realizando un estudio clínico de la efectividad y los costos de los programas de aplicación de flúor llega a la misma conclusión, también es coherente con lo que afirma Székely et al. (2010) que también fue un estudio de concentración de flúor en saliva aunque fue con un grupo etario distinto ya que dicho estudio se realizó en adultos jóvenes.

\section{AGRADECIMIENTOS}

A la Universidad de La Frontera que a través del proyecto DI09-0034, que financió nuestra investigación; al Departamento de Ciencias Básicas por facilitar la infraestructura para almacenar y analizar las muestras. Resultados preliminares fueron presentados en las XXIX Jornadas de salud pública de la Universidad de Chile, Santiago-Chile, 10 y 11 de noviembre de 2011. 
MUÑOZ, M. P.; ESPINOZA, E. G.; NUÑEZ, G. \& SANHUEZA, C. A. Availability of fluoride in saliva and biofilms in schoolchildren exposed to fluoride in water or milk. Int. J. Odontostomat., 9(3):393-398, 2015.

SUMMARY: Caries continue to be a public health problem, due to their high prevalence and their severe effect on people. Currently in Chile, adding fluoride to water and milk are public health measures to prevent caries that are distributed in urban and rural areas respectively. Scientific evidence supports the availability of fluoride in saliva and bacterial plaque being the most effective prevention against caries. The goal was to compare the levels of fluoride in saliva and bacterial plaque before and after drinking milk, among schoolchildren who consume fluoridated milk and those who consume un-fluoridated milk prepared with fluoridated drinking water, in the La Araucanía Region of Chile. A study was conducted of repeated samples of saliva and bacterial plaque in 165 children within the PAE program at 16 rural and urban schools. Saliva and bacterial plaque samples were taken before breakfast, saliva samples were taken 60 minutes after breakfast and bacterial plaque samples were taken $120 \mathrm{~min}$ after breakfast. The concentration of fluoride in saliva was found to be very similar regardless of the manner in which it was administered. So it was similar in children drinking fluoridated milk and un-fluoridated milk prepared with fluoridated water, and similar both before and after breakfast. In contrast, we found small differences for bacterial plaque, that are statistically significant. However, they may not be clinically significant as they are too small. These results reinforce the hypothesis that the strategy of adding fluoride to milk has similar results to adding fluoride to water.

KEY WORDS: fluoride, caries, prevention, saliva, fluoridated milk, fluoridated water.

\section{REFERENCIAS BIBLIOGRÁFICAS}

Boros, I.; Keszler, P. \& Bánóczy, J. Fluoride concentrations of unstimulated whole and labial gland saliva in young adults after fluoride intake with milk. Caries Res., 35(3):167-72, 2001.

Ekstrand, J. Fluoride concentrations in saliva after single oral doses and their relation to plasma fluoride. Scand. J. Dent. Res., 85(1):167, 1977.

Lynch, R. J.; Navada, R. \& Walia, R. Low-levels of fluoride in plaque and saliva and their effects on the demineralisation and remineralisation of enamel; role of fluoride toothpastes. Int. Dent. J., 54(5 Suppl. 1):304-9, 2004.

Mariño, R.; Morgan, M.; Weitz, A. \& Villa, A. The cost-effectiveness of adding fluorides to milk-products distributed by the National Food Supplement Programme (PNAC) in rural areas of Chile. Community Dent. Health, 24(2):75-81, 2007.

Mariño, R.; Villa, A. \& Guerrero, S. A community trial of fluoridated powdered milk in Chile. Community Dent. Oral. Epidemiol., 29(6):435-42, 2001.

Mitchell, C.; Craig, C. \& Wilson, D. National Health and Medical Research Council. A systematic review of the efficacy and safety of fluoridation. Part A: Review methodology and results. Sidney, Australian Government, National Health and Medical Research Council, 2007.

Nakano, T.; Neale, C.; Robinson, C.; Sakakibara, S.; Komoto, S.; Nakagaki, H. \& Fukuta, O. Effect of low level fluoride on demineralization kinetics of human dental enamel. Pediatr. Dent. J., 21(2):160-4, 2011.

Naumova, E. A.; Sandulescu, T.; Bochnig, C.; Gaengler, P.; Zimmer, S. \& Arnold, W. H. Kinetics of fluoride bioavailability in supernatant saliva and salivary sediment. Arch. Oral Biol., 57(7):870-6, 2012.

Newby, E. E.; Martinez-Mier, E. A.; Zero, D. T.; Kelly, S. A.; Fleming, N.; North, M. \& Bosma, M. L. A randomised clinical study to evaluate the effect of brushing duration on fluoride levels in dental biofilm fluid and saliva in children aged 4-5 years. Int. Dent. J., 63(Suppl. 2):39-47, 2013.
Petersson, L. G.; Arvidsson, I.; Lynch, E.; Engström, K. \& Twetman, S. Fluoride concentrations in saliva and dental plaque in young children after intake of fluoridated milk. Caries Res., 36(1):40-3, 2002.

Székely, M.; Fazakas, Z.; Balogh-Samarghitan, V.; Bánóczy, J. \& Tóth, $Z$. Fluoride excretion in whole saliva and urine after intake of fluoridated milk with or without breakfast in young adults. J. Oral Health Dent. Manag., 9(4):207-13, 2010.

Twetman, S.; Nederfors, T. \& Petersson, L. G. Fluoride concentration in whole saliva and separate gland secretions in schoolchildren after intake of fluoridated milk. Caries Res., 32(6):412-6, 1998.

Vallejos, V. C.; Lorca, O. P. \& Orellana. C. J. J. Análisis de la evidencia publicada sobre efectividad y riesgos de la fluoración del agua potable para la prevención de caries dentales. Santiago de Chile, Ministerio de Salud de Chile, Universidad de La Frontera, 2002. Disponible en http://web.minsal.cl/portal/url/item/ a1eb519e7e9c4592e04001011f01798b.pdf

Weitz, A.; Mariñanco, M. I. \& Villa, A. Reduction of caries in rural schoolchildren exposed to fluoride through a milk-fluoridation programme in Araucania, Chile. Community Dent. Health, 24(3):186-91, 2007.

Yeung, C. A. A systematic review of the efficacy and safety of fluoridation. Evid. Based Dent., 9(2):39-43, 2008.

Yeung, C. A. \& Tickle, M. Fluoridated milk for preventing dental caries in children and adolescents (Protocol). Cochrane Database Syst. Rev., 3:CD003876, 2002.

Dirección para Correspondencia:

Gerardo Espinoza Espinoza

Odontólogo, Magister Epidemiología Clínica

Docente Asistente

Departamento Salud Pública

Universidad de La Frontera

Temuco - CHILE

Email: gerardo.espinoza@ufrontera.cl

Recibido : 08-04-2015

Aceptado: 24-09-2015 